\title{
Üniversite Kariyer Merkezlerinin Dünyadaki Gelişimi ve Türkiye Örneği ${ }^{1}$
}

\author{
Neşe GÜLMEZ* Mehmet Emin OKUR ${ }^{* *}$
}

ÖZET

Gençlerin daha iyi bir kariyere sahip olma istekleri yükseköğretime olan ilgiyi her geçen gün önemli oranda arttırmaktadır. Gelişmiş ülke örnekleri incelendiğinde ise öğrencilerin bu talebini karşılamak üzere, istihdam edilebilirliği arttırmak ve kariyer gelişimini desteklemek amacıyla üniversitelerde Kariyer Merkezleri’nin kurulduğu görülmektedir. Bu merkezlerin, öğrenciler dışında işverenler, eğitim kurumları ve devletler için de önemli olduğu bilinmektedir. Mevcut çalışmada, çeşitli paydaş grupları için kritik önem arz eden "Kariyer Merkezlerinin” ülkemizdeki ve farklı kültürlerdeki tarihsel gelişimi sistematik bir yaklaşımla ortaya koyulmaktadır.

Araştırma Makalesi

Geliş: 19.01.2021

Kabul: 01.02.2021

Anahtar Kelimeler:

Üniversite Kariyer

Merkezi,

Kariyer Hizmetleri,

Kariyer Planlama,

Yükseköğretimde

İstihdam.

\section{The Development of University Career Centers in the World and its Example in Turkey}

\section{ABSTRACT}

The desire of young people to have a better career is increasing the interest in higher education every day. According to examples of developed countries, it is clearly seen that Career Centers were established in universities in order to meet this demand of students by increasing their employability and supporting their career development. It is known that these centers are important not only for students but also for employers, educational institutions and governments. Present study puts forward, the historical development of "Career Centers", which are critical for different stakeholders with a systematic approach both in Turkey and in different cultures.
Research Article

Received: 19.01 .2020

Accepted: 01.02.2021

Keywords:

University Career

Centers,

Career Services,

Career Planning,

Employment in Higher

Education

\footnotetext{
${ }^{1}$ Marmara Üniversitesi Sosyal Bilimler Enstitüsünde hazırlanan “Üniversite Kariyer Merkezi Hizmetlerinde Dijital Platform ve Sosyal Medya Kullanımının Etkisi” başlıklı doktora tezinden üretilmiştir.

* Doktora Öğrencisi, Marmara Üniversitesi, Sosyal Bilimler Enstitüsü, İşletme Ana Bilim Dalı, nesegulmez@gmail.com, ORCID ID: https://orcid.org/0000-0002-9739-6528

** Doç. Dr., Marmara Üniversitesi, Yönetim ve Organizasyon Anabilim Dalı, mokur@marmara.edu.tr, ORCID ID: https://orcid.org/0000-0002-6079-8160
} 


\section{GíRiş}

Ülkemizde gençlerinin üniversite eğitimi alma talebi diğer pek çok ülkede olduğu gibi her geçen gün artmaktadır. Ekonomik İşbirliği ve Kalkınma Örgütü (OECD) raporları, OECD üyesi ülkelerde 2009 ile 2019 yılları arasında üniversite eğitimi alan gençlerin sayısında ortalama \%10 artış olduğunu göstermekteyken Türkiye'de bu oran \%19'dur (OECD, 2020a). Araştırmalar ise yükseköğretime devam etme talebindeki bu artışın, "daha iyi kariyer firsatlarına ulaşabilme” isteğinden kaynaklandığını göstermektedir (Bara Stolzenberg ve diğerleri., 2020; Carlson, 2017; Royal, 2020).

İşü̈cü piyasalarındaki insan kaynağı ihtiyacı dikkate alındığında, gençlerin bu kararı şaşırtıcı değildir. Yakın tarihli OECD raporları; teknolojik ilerleme ve küreselleşme nedeni ile birçok ülkede üniversite eğitimi almayan gençler için işgücü piyasası koşullarının kötüleştiğini, gençlerin iş bulmakta zorlandıklarını, niteliklerinin altında işlerde ya da hak ettiklerinden düşük ücrete çalışmak zorunda kaldıklarını göstermektedir (OECD, 2019).

Yükseköğretim mezunu bireyler daha düşük eğitim seviyelerine sahip olanlara göre avantajlı durumda olsa da bu durum istihdam problemi yaşamadıklarının bir göstergesi değildir. Ülkemiz de dâhil olmak üzere bugün pek çok ülke, genç işsizliği ile mücadele etmektedir ve söz konusu kitlenin önemli bir bölümünü üniversite eğitimine sahip bireyler oluşturmaktadır (OECD, 2020b).

Gelişmiş ülke örnekleri incelendiğinde, mezunların istihdam edilebilirliklerini arttırmak ve öğrencilerin kariyer gelişimlerini desteklemek amacıyla üniversitelerde Kariyer Merkezleri kurulduğu görülmektedir. Kabul gören anlayışa göre; Kariyer Merkezlerinin temel amacı; kariyer, eğitim, istihdam ve girişimcilik kararları ve planlarını desteklemek geliştirmek ve/veya uygulamak konusunda öğrencilere / mezunlara ve ilgili diğer taraflara yardımcı olmaktır (NACE, 2019). Söz konusu merkezlerin hizmetleri ise öğrencilerin kariyer gelişimlerini destekleyerek üniversiteden profesyonel hayata geçişte onlara yardımcı olmaya odaklanmıştır (Vinson, Reardon ve Bertoch, 2014) ve işverenler, eğitim kurumları ve hatta devletler için de önemli bir aracı durumundadır. (A. G. Watts, 1996).

Mevcut çalışma, çeşitli paydaş grupları için kritik önem arz eden "Kariyer Merkezlerinin" farklı kültürlerdeki tarihsel gelişimini incelemektedir. Söz konusu incelemelerin literatüre anlamlı bir katk1 yapması beklenmekte ve ülkemizde bu alanda çalışan akademisyenlere kariyer merkezlerinin gelişim süreçleri hakkında kapsamlı bir tarama sunarak çalışmaları için başlangıç noktası oluşturması amaçlanmaktadır. Ayrıca, farklı ülkelerdeki üniversite kariyer merkezlerinin gelişimindeki tetikleyici faktörlere dair çıkarımların Türkiye'deki kariyer merkezi yönetici ve uzmanları, akademisyenler ve alanda çalışan profesyoneller için yol gösterici olması beklenmektedir. 


\section{KURAMSAL ÇERÇEVE}

Bugün farklı isimler altında anılsa da genellikle "Kariyer Merkezi" ismini taşıyan üniversite birimlerinin tarihi; İngiltere'de, Oxford Üniversitesi tarafından 1892 yılında kurulan “Appointment Committee" isimli birim ile başlamaktadır (Barbour, 2016; UNESCO, 1994). Yaklaşık 130 y1llık geçmişe sahip kariyer merkezleri günümüzde gelişmiş ülkelerdeki tüm üniversitelerde bulunan bir birim haline gelmiştir. Ülke fark etmeksizin, söz konusu birimlerin gelişim sürecinde özellikle ekonomik faktörler ortak bir etkiye sahipse de ülkenin koşullarına göre; kuruluş, yaygınlaşma ve gelişim aşamalarında değişiklik gözlenmektedir.

$\mathrm{Bu}$ doğrultuda mevcut çalışmada; üniversite kariyer hizmetlerinin temelini oluşturan Anglosakson ülkelerden Birleşik Krallık ve Amerika Birleşik Devletleri ile birlikte; aynı kültürden Avustralya ve Kanada'daki kariyer merkezlerinin tarihsel gelişimi incelenmiştir. Kıta Avrupası yaklaşımını ortaya koymak adına nüfusça ülkemize benzer Almanya ve Fransa'daki gelişmeler ele alınmıştır. Tamamen farklı kültürlerdeki örneklerine değinebilmek adına Asya-Pasifik ülkelerinden Güney Kore, Japonya ve Çin'deki üniversitelerin kariyer hizmetlerinin tarihsel gelişimleri de araştırmaya konu edilmiştir. İnceleme için seçilen ülkelerin tamamının, 25-34 yaş aralığındaki üniversite mezunlarının istihdam oranının karşılaştırıldığı "Education at a Glance 2020" raporuna göre, ülkemizden daha üst sıralarda olmasına dikkat edilmiştir (OECD, 2020a). Son olarak Kariyer Merkezlerinin ülkemizdeki gelişim seyri ve mevcut durumları ele alınmıştır.

\section{Kariyer Merkezlerinin Doğuşu ve Anglosakson Ülke Uygulamaları}

Yükseköğretimde öğrencilere kariyer hizmeti sunma kültürü, günümüzde genellikle kariyer merkezleri ismi ile anılan birimler aracılığıyla başlamıştır. Oxford Üniversitesi ise 1892 yılında kurduğu “Appointment Committe” isimli birimi ile üniversitelerde örgütlü olarak profesyonel kariyer hizmeti sunmanın dünyadaki ilk örneği oluşturmuştur (Barbour, 2016; UNESCO, 1994).

Cambrigde Üniversitesi 1914 yılında kurduğu “Appointment Board” ile Oxford Üniversitesinin bu girişimini takip etmiştir (Schoenberg, 1978). Amerika'nın en eski üniversitelerin bulunduğu Ivy League'e mensup Yale Üniversitesi de "Placement Office” ile 1919 yılında Amerika kıtasında kariyer merkezi uygulamasına geçen ilk üniversite olmuştur (Gonzales, 2017).

Birleşik Krallık üniversitelinin, diğer ülkelere kıyasla öğrencilerinin bireysel gelişimleri ile daha fazla ilgilenmesi aslen İngiliz örf ve adet hukukundaki bir doktrine dayanmaktadır. Kariyer merkezleri de, bu ilginin doğal bir sonucu olarak, ilk kez İngiltere'de ve takiben de aynı doktrine kendi kanunlarda yer veren Amerika Birleşik Devletleri’nde görülmüştür. İngiltere ve Amerika Birleşik Devletleri’ndeki eğitim kurumlarının öğrencilerinin kariyer gelişimlerine ilişkin felsefesinin dayandığı söz konusu 
doktrin, Latince "bir ebeveyn yerine" anlamina gelen in loco parentis"tir. (P. Lee, 2011; A. Watts, 1994; A. Watts ve Van Esbroeck, 2000). Bu doktrine göre öğrencilerin sağlığından, güvenliğinden, ahlakından ve refahından fiili ve yasal olarak vasisi sayılan üniversiteler sorumlu tutulmaktaydı (Szablewicz ve Gibbs, 1987).

Avustralya'da kariyer merkezi girişiminin temelleri ise İngiltere'deki çalışmaların etkisi ile başlamıştır. İlk örnekleri ise 1920'li y1llarda Sidney, Melbourne, Adelaide ve Queensland üniversitelerinde verilen danışmalık ve istihdam odaklı hizmetlere dayanmaktadır (Koder, 1991; Mckenzie ve Howell, 2005).

Aynı kültüre mensup, bu üç farklı ülkede birbirine yakın tarihlerde hizmet vermeye başlayan söz konusu birimler, isimlerinden de anlaşılacağı üzere; öğrencilere boş pozisyonların duyurulması, mülakatlar ayarlanması gibi “işe yerleştirmeye” odaklanmaktaydı (Koder, 1991; Mckenzie ve Howell, 2005; Teal ve Herrick, 1962; A. G. Watts ve diğerleri., 1996).

Kanada'da ise merkezlerin kurulup gelişmesi farklı bir ihtiyaçtan doğmuştur, ülke genelinde kariyer ve istihdam hizmetleri genel olarak ikinci dünya savaşından dönen askerlerin sivil hayata geçişini kolaylaştırmak, yükseköğretime devam etmelerini veya iş hayatına kazandırılmaları sağlamak amacıyla 1950'li yıllarda başlamıştır. 1960'larda yaşanan doğum hızındaki büyük artış, yükseköğretim kurumlarında öğrenim gören genç sayısında ciddi bir yükselmeye sebep olarak bu hizmetlerin önemini arttırmıştır. (Bezanson, Hopkins ve Neault, 2016; Cox ve Strange, 2010; Usher, Kwong ve Mentanko, 2014). Söz konusu hizmetlerin, üniversite öğrencilerini iş piyasasındaki rekabette daha donanımlı hale getirmeyi destekleyecek şekilde gelişmesi ise hem artan işsizlik hem de Kanada Federal Devleti'nin kişilerin eğitim ve ilgi alanlarıyla uyumlu işlerde çalışmasını sağlayacak politikaları üretmeye başlaması ile 1970’lere doğru mümkün olmuştur (Bezanson, Hopkins ve Neault, 2016).

Kanada'da kariyer hizmetlerine ilişkin çalışmaların başlayıp profesyonelleşmeye yönelik ilk adımlarının atıldığı tarihlerde; İngiltere, Amerika ve Avustralya'da söz konusu hizmetlerin ikinci aşamaya geçtiği görülmektedir. İngiltere'de kariyer merkezi hizmetleri 1950'li yılların ortalarında tüm üniversitelerde yaygınlaşma sürecini tamamlamıştır. 1960’lara kadar öğrenciler üniversiteye girdiklerinde kariyerleri ile ilgili bir karara zaten varmış oldukları düşünülerek kariyer danışmanlığı geri planda kalmış, hizmetler daha çok bilgi sağlama, yerleştirmeyi desteklemeye ve çeşitli etkinlikler düzenlemeye odaklanmıştır. 1960'ların sonunda ise kariyer alternatiflerinin sayısının artması ile öğrencilerin tercih yapmasını kolaylaştırmak üzere kariyer danışmanlığının önemi artmıştır. 1973 yılında çıkarılan İstihdam ve Eğitim Kanunu ile "Genç İstihdam Hizmeti”, "Kariyer Hizmetine” 
dönüştürülerek yerel eğitim makamlarının bu hizmeti sunması yasal bir zorunluluk haline getirilmiştir. İstihdam Ofislerinin isimleri de Kariyer Ofisleri olarak değişmiştir (A. G. Watts ve Kidd, 2000).

Amerika'da; 1940 ve 1960 arasında; öğrencilere kariyer danışmanlığı sunmanın önemi "İkinci Dünya Savaşı sonrasında hızla büyüyen Amerika Birleşik Devletleri ekonomisi” ve "Sovyet Sosyalist Cumhuriyetler Birliği’nin uzay çalışmaları” etkisiyle artmıştır (Onne Kraning, 1999; Pope, 2000). Bu gelişmelerin etkisi ile yürütülen hizmetler incelendiğinde 1950'lerde işe yerleştirme ve kariyer planlamanın ayrı hizmetler olarak algılandığı ve hatta yönetimleri ve ofisleri birbirinden ayrı iki birime dönüştürüldüğü görülmektedir. 1960’larda ise kariyer gelişimine ağırlık verilmiş, söz konusu iki hizmet birbirini tamamlar şekilde tek bir yapı altında birleştirilmeye başlanmıştır (Geisler, 2002). Ekonomik büyümenin 1970'lerde yavaşlaması sonucu iş gücü piyasasının istihdam imkânı azalmış, bu değişimden üniversitelerin yerleştirme merkezleri de etkilenmiştir. Bu yeni koşullar doğrultusunda “öğrenciye ebeveynlik etme” anlayışı yerini “öğrenciyi geliştirme ve kariyer planlama” anlayışına bırakmıştır. Dolayısıyla; işe yerleştirme göreviyle kurulmuş kariyer merkezlerinin yerleştirme fonksiyonu odak noktası olmaktan çıkmış ve yerleştirme kariyer planlamanın bir sonucu olarak ele alınmaya başlanmıştır. Bu yeni anlayış ise 1980’li yıllar boyunca hâkimiyetini korumuştur. (Bishops, 1966).

Kuruluş aşamasında olduğu gibi Avustralya'daki gelişmeler Birleşik Krallık ve Amerika Birleşik Devletleri ile paralellik göstermiştir. 1960’lı yılların başında yaşanan; üniversite sayısının ve çeşitliliğinin artması, demografik, sosyal ve ekonomik değişimler doğrultusunda kariyer hizmetlerin de sayısı ve çeşitliliği artmış, istihdam odaklı hizmet anlayışından kariyer planlama anlayışına doğru bir geçiş yaşanmıştır. Bu anlayış 1990’lara kadar sürdürülmüştür (Niles ve Harris-Bowlsbey, 2002).

Anglosakson ülkelerin kariyer hizmetleri anlayışındaki bir sonraki dönüşüm ise 1980'lerin sonunda, 1990’ların başında yaşanmıştır. Birleşik Krallıkta 1980’lı yıllardan itibaren kariyer merkezleri sürekli olarak gelişen teknolojiyi yakalamak üzere çalışmıştır (Hooley, Hutchinson ve Watts, 2010). Bu çalışmaların yanı sıra 1990'larda kariyer eğitimi okullarda müfredatın zorunlu bir parçası haline getirilmiş, kariyer hizmetleri ise yerel otoritelerin zorunlu olarak verdiği bir hizmet olmaktan çıkarılıp rekabetin bir gerekliliği olarak verilmeye başlanmıştır (A. G. Watts ve Kidd, 2000).

Aynı yıllarda Amerika'da kariyer planlama modeli yerini ağ oluşturma (networking) modeline bırakmaya başlamıştır. Yerleştirme ve kariyer planlama uygulamaları o yıllarda hala devam etse de kariyer hizmetlerinde yaygın olarak ağ oluşturma modeli kullanılmıştır (Castella, 1990). 1980-1990 yılları arasında sanayi çağından bilgi çağına geçiş ve kariyer danışmanlığı ile işten çıkarma 
danışmanlığının gelişimi ön plana çıkmışken, 1990'lardan itibaren danışmanlık alanında gelişen teknolojilerin kullanılması odak nokta olmuştur (Pope, 2000).

Avustralya'da da, 1990'lardan itibaren teknolojik gelişmelerin etkisi ile üniversite kariyer hizmetlerinde bir dönüşüm yaşanmış, bu durum 2000'lerde etkisini arttırmıştır (Mckenzie ve Howell, 2005). Kariyer gelişimi alanında profesyonelleşme dönüşümü de 2000'li yıllarda mümkün olmuştur. Bu dönemde, profesyonel meslek birlikleri üniversitelerde kariyer hizmeti veren çalışanlar için belirli standartların oluşturulması amacıyla çalışmalar başlatmıştır (Cox ve Strange, 2010; Domene ve Isenor, 2017; Mckenzie ve Howell, 2005).

Birleşik Krallık ve Amerika'da 1980'ler Avustralya'da ve Kanada'da ise 2000'li yıllarda yaşanan bu dönüşümler söz konusu ülkelerde kariyer merkezlerinin bugünkü haline evrilme sürecini başlatmıştır.

Günümüzde bu ülkelerde kariyer merkezlerinin sunduğu hizmetler incelendiğinde tüm ülkelerde benzer faaliyetler göze çarpmaktadır. Bunlar; kariyer danışmanlığı, özgeçmiş oluşturma, mülakat becerileri kazandırma, ăg oluşturma, kariyer fuarları, işverenlerce aranan sosyal becerileri kazandırmak ve / veya kariyer bilgisi sağlamak üzere düzenlenen etkinlikler ve iş ilanları şeklinde siralanabilmektedir (Browne ve Russell, 2014; Cox ve Strange, 2010; Long, Hubble ve Loft, 2020; Rainey ve diğerleri., 2008; Shepard ve Mani, 2013; Usher, Kwong ve Mentanko, 2014).

\section{Kita Avrupa'sında Üniversite Kariyer Hizmetleri}

Almanya, kariyer ve meslek danışmanlığı konusunda vatandaşlarına hayatları boyunca destek olma anlayışını benimsemiştir. Bu doğrultuda; kariyer hizmetleri sorumluluğu; federal hükümet, yerel hükümetler, belediyeler, Federal İstihdam Kurumu, ticaret ve meslek odaları, yükseköğretim kurumları ve okullar arasında paylaşılmaktadır. Gençlere / yetişkinlere kariyer hizmeti sunmak ise yasal bir zorunluluktur, kariyer eğitimi ve mesleki eğitim tüm ortaöğretim kurumlarında müfredatın ayrılmaz bir parçasıdır. Bu eğitimler, kariyer yönetim becerilerini, bilgiyi arama ve kullanma ve karar verme becerilerini geliştirerek tüm öğrencileri iş hayatına hazırlamayı amaçlar (Jenschke, Schober ve Langner, 2014). Dolayısıyla Alman ortaöğretiminden geçerek üniversiteye gelen bireyler için yükseköğretim süreci, kariyer planlama aşamasının bir sonucu olarak değerlendirilebilir. Yükseköğretim seviyesinde sunulan kariyer hizmetleri incelendiğinde; Almanya üniversitelerinde 1990’1ı yıllara kadar bu hizmetlerin sunulmadığı, söz konusu yıllardaki ilk örneklerinin ise uygulamalı bilimler üniversitelerinde yer aldığı görülmektedir (Brandl, Polenova ve Savoca, 2011).

Benzer şekilde Fransa'da da üniversitelerde kariyer hizmetlerinin verilemeye başlaması 1990'larda başlamıştır. Bunun nedeni ise yükseköğretime olan talebin 1970'lerde çok hızlı şekilde artmaya başlayıp 1990'larda mezun sayısının 1970'lerdekinin 5 katına ulaşmış olmasıdır. Söz konusu artış, iş 
piyasasındaki rekabeti arttırdığı için, üniversiteleri öğrenci ve mezunlarının iş dünyasına geçişini kolaylaştıracak çalışmalar yapmaya yönlendirmiştir. Bu doğrultuda, 1990’ların sonuna kadar Fransa'daki üniversitelerin yarısından fazlası da söz konusu çalışmaları yapmak üzere birimler kurmuş, mezunlarının istihdam durumunu araştıran anketler düzenlemeye, danışmanlık ve iş bulmaya yönelik hizmetler sağlamaya başlamıştır (Paul ve Murdoch, 2000).

Almanya'da söz konusu hizmetlerin 1990’lı yıllarda ivme kazanması ise yükseköğretim konusunda benimsediği stratejiler ile ilişkilendirilebilir. “Avrupa Yükseköğretim Alanı” yaratmayı hedefleyen Bologna Süreci ile Alman yükseköğretim kurumlarının stratejik olarak pazarlaması yapılmaya başlanmış, buna Anglosakson ülkelere olan beyin göçünün engellenmesi hedefleri de eşlik etmiştir (Trines, 2019). Dolayısıyla marka değerini yükselterek genç yetenekleri çekmek isteyen ve ülke dışından gelen öğrencilere de hizmet veren yükseköğretim kurumlarının, kariyer merkezlerini hızla kurmalarına neden olduğu düşünülebilir.

Fransa' da 2000'lerin başında üniversitelerde verilen kariyer hizmetlerinin önemine ilişkin farkındalık ülke genelinde artmış ve söz konusu hizmetlerin verilmesi kanunlar ile garanti altına alınmıştır. İlki 2007 çıkarılan ve 2013 ve 2018'de güncellenerek güçlendirilen kanunlar aracılığıyla üniversiteler öğrencilerin kariyer gelişimlerini desteklemekten sorumlu tutulmuştur (EURYDICE, 2018). Kariyer hizmetlerinin çerçevesi ilgili kanunlarca belirlenen ulusal politikalar doğrultusunda çizilmekteyse de yükseköğretim kurumlarının özerkliği kapsamında, üniversite kararıyla öğrencilere kariyer hizmeti verme amacını taşıyan birimler kurulduğu da görülmektedir. Günümüzde bu birimler; fuarlar, atölyeler, seminerler, istihdam odaklı hizmetler sunmakta ve öğrenciler için sanal ve fiziksel kaynaklar sağlamaktadır (EUROGUDIENCE, t.y.). Bunlar ek olarak bazı üniversiteler eğitim ve kariyer anlamında dezavantajlı sayılabilecek gruplara özel hizmetler de sunmaktadır (Crosier ve diğerleri., 2015). Ancak Doğu Paris Üniversitesi’ndeki öğrencilerle yapılan bir çalışmada, öğrencilerin üniversiteye başlamadan önce ve üniversitedeki ilk yıllarında yeterli kariyer hizmeti almadığı ve bunun Fransız öğrencilerin geneli için geçerli bir durum olduğu belirtilmektedir. (Crosier ve diğerleri., 2015). Almanya'daki öğrencileri, üniversiteden iş hayatına geçişte destekleme temel amacını taşıyan kariyer merkezleri günümüzde tüm yükseköğretim kurumlarında bulunmaktadır. Bu merkezler, yerel iş bulma bürolarındaki uzmanlar, işveren birlikleri, ticaret odaları, yerel ya da küresel şirketler ile iş birliği içinde çalışmakta, dahası, mezunların temel yetenekleri geliştirmeye yönelik çalışmaların ve lisans programlarının geliştirilmesi konularına da dâhil olmaktadır (Jenschke, Schober ve Langner, 2014). Üniversitelerdeki kariyer hizmetlerinde "rehberlik ve danışmanlık", "akademi-işgücü piyasası bağlantısı" ve "iletişim ağı" olmak üzere üç konuya dikkat çekilmekte ve bu bağlamda öğrencilerin bireysel rehberlik, danışmanlık, koçluk, iş birliği projeleri, mezunlar ile mentorluk, atölye çalışmaları 
vb. hizmetler ile desteklendiği belirtilmektedir (Gillani ve Keller, 2018; Tomei, Carp ve Kröner, 2015). Ayrıca son dönemdeki kariyer hizmetleri, internet tabanlı uygulamalar ile güçlendirilmektedir. Dahası, kariyer hizmetlerinin elektronik ortamda verilmesi konusunda da Alman Rektörler Birliği ve Federal İstihdam Kurumunun iş birliği ile geliştirdiği çalışmalar da bulunmaktadır (Jenschke, Schober ve Langner, 2014).

\section{Asya Pasifik Ülkelerinde Üniversite Kariyer Hizmetleri}

Güney Kore, Japonya ve Çin’deki üniversitelerde verilen kariyer hizmetlerinin erken dönem örnekleri incelendiğinde, söz konusu üç ülke arasındaki ilk çalışmaların Çin’de 1916 yılında Tsinghua Üniversitesi'nde kariyer gelişim derslerinin verilmesiyle başladığı bilinmektedir (Jin, 2017). Japonya ve Güney Kore'de ise bu erken dönem hizmetler 1950'lerde başlamıştır (J.-K. Lee ve Goh, 2003; Watanabe-Muraoka, 1996).

Hizmetlerin görevlendirilmiş bir birim aracılığıyla, örgütlü şekilde sunulması ilk kez Japonya’ da, 1953 yılında Tokyo Üniversitesinde açılan “danışmanlık merkezi” ile başlamaktadır (Watanabe-Muraoka, 1996). Japonya’yı Seul Ulusal Üniversitesinin 1962 yılında kurduğu “kariyer danışmanlığı” birimi ile Güney Kore izlemektedir (J.-K. Lee ve Goh, 2003). Üç ülke arasında kariyer hizmetlerine ilişkin çalışmalara en erken başlayan Çin'de ise ilk kariyer merkezi 1986'da Shenzhen Üniversitesi'nde kurulabilmiştir (CCLC, t.y.; Sun ve Yuen, 2012).

İlk kariyer merkezlerinin kuruluş tarihleri farklılık gösterse de, merkezlerin yaygınlaşması her üç ülkede de yükseköğretim kurumlarından mezun olan kişi sayısının ve dolayısıyla işgücü piyasasına dâhil olan nitelikli insan kaynağının hızla artması ile başlamıştır. Çünkü bu durum üniversiteleri, mezunların istihdam edilebilirliğini arttırmaları gerektiği gerçeği ile karşı karşıya bırakmıştır (J.-K. Lee ve Goh, 2003; Mimura, 2016). Söz konusu gelişmeler Güney Kore ve Japonya'da 1980'lerde yaşanmıştır. Çin'de ise 1980'li yıllara kadar yükseköğretim kurumlarından mezun olan kişi sayısının yüksek olmaması, mezun olan öğrencilerin kariyer planlamalarının, Marksist planlı ekonomik sistem içinde, katı bir şekilde devlet tarafından yapılması ve bu kişilerin yüksek rekabet olmaksızın devlet desteğiyle iş bulabilmesi, kariyer hizmetlerinin gelişmesi için ihtiyaç doğmasını engellemiştir. Bu ihtiyaç 1980'lerin sonunda ancak belirginleşmiştir. (Zhang, Hu ve Pope, 2002).

Güney Kore'de 1980 ile 1990 yılları arasında, öğrenci işleri daireleri altında kariyer gelişimi ile ilgili birimler hizmet vermeye başlamış ancak sadece iş ilanlarını öğrencilere ulaştırmaya odaklanan oldukça sınırlı hizmetler sunulmuştur. Kariyer hizmetlerini sağlayan personelin niceliği ve niteliği konusundaki eksikler ise bu dönemde öne çıkan sorunlar arasındadır (Yang, Lee ve Ahn, 2012). 1990'ların sonuna kadar artan hizmet ihtiyacına paralel olarak Güney Kore, kariyer merkezi 
hizmetlerini sunmakla görevli deneyimli personel grubu yetişmeye odaklanmıştır. Bu gelişmelere rağmen ikinci dönemdeki hizmetler birinci dönemde olduğu gibi öğrencilerin işe yerleşmelerine odaklanmıştır. Öğrencilere işverenleri tanıtma, iş başvuru süreçlerinde yardımcı olma ve öneriler sunma gibi hizmetler verilmiştir (Yang, Lee ve Ahn, 2012).

Japonya'da ise söz konusu tarihler arasında kariyer merkezi kurulan üniversite sayısı hızla artış göstermiştir. Araştırmalara göre bu birimler; 1983 yılında üniversitelerin yaklaşık \%35'inde, 1989 y1lına gelindiğinde ise \%75'inde bulunmaktadır (Watanabe-Muraoka, 1996). 1990'lar boyunca öğrencilerin istihdam edilebilirliğini desteklemek için üniversitelerde pek çok çalışma yürütülmüş ancak bu çalışmaların Amerika Birleşik Devletleri etkisi altında gerçekleştirildiğine dolayısıyla kimi kültürel uyuşmazlıklar barındırdığına dair eleştiriler almıştır (Kaneko, 2014; Senzaki, 1993; Watanabe-Muraoka, 1996; Watanabe-Muraoka, Senzaki ve Herr, 2001).

Çin'de ise 1990’lı yıllardan itibaren yükseköğretim kurumlarında öğrenim gören öğrenci sayısının daha da atması ve piyasa ekonomisi temelli yaklaşımların benimsenmesiyle kariyer planlama sorumluluğu devletten bireylere doğru kaymıştır. Mezun olan öğrenciler iş bulabilmek için ciddi bir rekabete girmek zorunda kalmış ve iş bulmakta güçlük yaşamışlardır. Bu durum, üniversitelerin kariyer merkezleri çalışmalarına ağırlık verilmesine neden olmuştur (Zhang, Hu ve Pope, 2002).

2000’li yıllara gelindiğinde; Güney Kore'de Hükumetin üniversite mezunlarının işsizliğiyle mücadele kapsamında geliştirdiği politikalar doğrultusunda, tüm üniversitelerde kariyer merkezleri kurdurulmuş ve bu merkezlere mali destek sağlanmıştır (Yang, Lee ve Ahn, 2012). Söz konusu gelişmeler; kariyer merkezlerindeki kariyer danışmanlığı ve kariyer keşfi konularında yeni hizmetler verilmesini sağlasa da işe yerleştirme odaklı hizmetlerin ağırlığı devam etmiştir (Han ve Heo, 2008). Bu duruma sebep olarak ise; ilgili bakanlıkların mezun istihdam oranlarına ilişkin verileri açıklayarak üniversiteler üstünde baskı yaratması ve öğrencilerin doğrudan istihdamla ilgili hizmetleri daha fazla talep etmesi gösterilmektedir (Yang, Lee ve Ahn, 2012).

Japonya'da yapılan çalışmalar 2000'li yılların başı itibari ile üniversitelerin \%92'sinde kariyer merkezlerinin bulunduğunu ve bu merkezlerin daha çok işe yerleştirme odaklı hizmetler sunduğunu göstermektedir. Çalışmalara göre bu merkezlerin \%78'den fazlasında staj programları kullanılmakta ancak sistematik ve kapsamlı kariyer gelişimi hizmeti sunanlar yaklaşık \%41 ile sınırlı kalmaktadır (Ishikawa, Mizuno ve Amundson, 2009).

Çin'de kariyer hizmetleri; öğrencilerin iş bulmalarını kolaylaştırmaya odaklanan "istihdam danışmanlığı" ve hayat boyu kariyer gelişimini desteklemeyi hedefleyen "kariyer planlama" olmak üzere iki başlık altında devam etmektedir. Söz konusu hizmetler; 1998-2001 arasında istihdam 
danışmanlığ 1,2002 ve sonrasında ise kariyer planlama kavramı ön planda olacak şekilde yürütülmüştür (Hao, Sun ve Yuen, 2015).

Son yıllarda ise; her üç ülkede de kariyer hizmetleri anlamında devlet destekli büyük iyileştirmeler geçekleştirilmiştir.

Yükseköğretimden mezun olan insan kaynağının planlanması konusunda artan ihtiyaca binaen Çin Eğitim Bakanlığı 2007 tarihinde yayınladığı “Üniversite Öğrencilerinin Kariyer Müfredatına İlişkin Gereklilikler” ile yükseköğretim kurumlarını, müfredatlarına zorunlu kariyer dersi eklemeleri ve öğrencilere kariyer danışmanlığı verecek sistemi inşa etmeleri yönünde teşvik etmiştir. 2010 yılında ise üniversitelerin mezunlara da kariyer rehberliği hizmetleri sunması yönünde görüş paylaşmıştır (Jin, 2017).

Japonya'da Merkezi Eğitim Kurulu tarafından 2011'de yayınlanan ve hükümetçe desteklenen “Okullarda Kariyer Eğitimi ve Mesleki Eğitim Hakkında Gelecek Vizyonu” raporu ile üniversitelerde kariyer eğitimi programları açılması teşvik edilmiştir (Kaneko, 2014). Günümüzde Japonya' da kariyer hizmetleri farklı bakanlıkların iş birliğiyle yürütülmektedir (Mizuno, Ozawa ve Matsumoto, 2017).

Benzer şekilde Güney Kore'de alandaki büyük gelişimlerden biri 2015 yılında çıkarılan "Kariyer Eğitimi Kanunu” ile yaşanmıştır. İlgili kanunda "yükseköğretim kurumlarının öğrencilerine kariyer eğitimi sağlayabileceğii” ve "Eğitim Bakanlığının bu konuda kurumlara gerekli desteği verebileceği” hükümleri yer almıştır (KLRI-KLT, 2015). Bu doğrultuda; ilgili Bakanlık tarafından 2016'da hazırlanan 5 yıllık eğitim planında ise kariyer gelişimi ve eğitiminin, eğitim sisteminin farklı seviyelerinde planlaması yapılmıştır. Bu çalışmada; ilkokul seviyesinde "kariyer farkındalığı", ortaokulda "kariyer keşfi", lisede "kariyer planlama", ve üniversitede "kariyer seçimi” süreçlerine odaklanan bir plan hazırlanmıştır (Yoon ve Pyun, 2018).

Günümüzde, Güney Kore'de kariyer merkezleri tarafından iş bulmaya yönelik kariyer fuarları, işveren toplantıları, işe yerleştirme hizmetleri, kariyer etkinlikleri (fuarlar, işveren toplantıları vb.) düzenlendiği, kariyer danışmanlığı sağlandığ 1 ve bunların yanı sıra bazı hizmetlerin çevrimiçi de sunulduğunu görülmektedir (Han ve Heo, 2008; J.-Y. Lee, 2001; OECD, 2002).

Japonya'da kariyer merkezlerince verilen hizmetler; mezunlarla ilişkiler, iletişim yönetimi, staj programları, iş / staj ilanları, işveren işbirlikleri vb. olarak sıralanabilir (Saito ve Pham, 2020). Ayrıca birçok ülkeye benzer şekilde öncelikle 3. sınıf ve üzeri öğrenciler için başlatılan istihdam hizmetlerinin günümüzde kariyer merkezleri aracılığı ile 1. sınıftan itibaren sağlandığı bilinmektedir (Kawasaki, 2006). 
Çin'de ise kariyer merkezleri; istihdam danışmanlığı kapsamında, işe alım süreçleri, özgeçmiş hazırlama, mülakat teknikleri gibi konularda hizmet vermekte, kariyer planlama kapsamında ise öğrencilere iş dünyası hakkında bilgiler sağlayıp kariyer kararları hakkında farkındalıkları arttırılmaya çalışılmaktır (Hao, Sun ve Yuen, 2015; Sun ve Yuen, 2012; Zhang, Hu ve Pope, 2002). Ayrıca öğrencilere kariyer odaklı dersler, kariyer fuarları, birebir danışmanlık hizmetleri, kariyer web sayfaları aracılığıyla bilgi, yazılı kaynaklar, seminerler, atölye çalışmaları ve staj olanakları sunulduğu da bilinmektedir (Jin, 2017; Sun ve Yuen, 2012).

\section{Türkiye}

Ülkemizde yapılan akademik çalışmalarda Üniversite Kariyer Merkezlerinin ilk örneği olarak Orta Doğu Teknik Üniversitesi’nin (ODTÜ) “İș Bulma Bürosu” isimli birimi gösterilmekte ve farklı araştırmalarda kuruluş yılı 1980 olarak ifade edilmektedir (Karaaslan, 2017; Kozak ve Dalkıranoğlu, 2013; Özden, 2015; Pişkin ve Ersoy Kart, 2019). Ancak, bugünkü adı ile "Kariyer Planlama Uygulama ve Araştırma Merkezi” web sayfasında, 1999 yılında Rektörlüğe bağlı birim olarak kurulduğu bilgisini paylaşılmaktadır (ODTÜ-KPM, t.y.). Geçmiş çalışmalarda referans gösterilen 1980 tarihinin nerden geldiğine yönelik araştırmalar sırasında, 1988 yılında yayınlanmış, ODTÜ’deki gelişmelere ilişkin bilgiler içeren "Katılım” dergisine rastlanmıştır. Söz konusu kaynakta, İş Bulma Bürosunun Ocak 1987'de "mezunları uzun süre çalışabilecekleri, ruhsal ve parasal açıdan tatmin olabilecekleri bir işe yerleştirmek amaciyla" kurulduğu bilgisine ulaşılmıştır (Baltan, 1985). Bu bilgi doğrultusunda, mevcut çalışmada ülkemizde ilk kariyer merkezini kuran üniversite ODTÜ olarak kabul edilmiştir. ODTÜ'yü takiben, 1988 yılında kariyer merkezi kuran İhsan Doğramacı Bilkent Üniversitesi bu girişimi ile vakıf üniversitelerindeki ilk kariyer merkezi örneğini oluşturmuştur (Bilkent-KM, t.y.).

Dolayısıyla; ülkemizdeki ilk üniversite kariyer merkezi örneklerinin; gelişmiş ülkelerde söz konusu merkezlerin ülke geneline yaygınlaşmansın tamamlandığı tarihte ancak kurulduğu görülmektedir. Üniversitelerde kariyer merkezleri kurulmasına öncülük eden Birleşik Krallık ve Amerika Birleşik Devletleri ile karşılaştırıldığında ise, kariyer merkezlerinin bu ülkeler genelinde yaygın hale gelmesinden yaklaşık 40 yıl sonra (Bishops, 1966; A. G. Watts ve diğerleri., 1996) ülkemizdeki ilk kariyer merkezinin kurulmuş olması durumu daha çarpıcı hale getirmektedir. Merkezlerin ülke genelinde yaygınlaşma süreci ise ancak, 2018 yılındaki Cumhurbaşkanlığı İnsan Kaynakları Ofisi Başkanlığı'nın (CBİKO) kurulması ile mümkün olmuştur.

2015 yılında 32 kariyer merkezi üzerinden yürütülen çalışmada, ülkemizdeki devlet üniversitelerindeki kariyer merkezlerinin \%60’ının 2012-2014 yılları arasında, \%40’ının ise 2015 yılında, uygulama ve araştırma merkezi statüsünde kurulduğu ifade edilmiştir (Özden, 2015). İstanbul'daki Kariyer merkezleri üzerinden, üniversite kariyer merkezlerinin genel yapısının 
incelendiği 2017 tarihli araştırmada; İstanbul'da, 5'i devlet ve 41'i vakıf olmak üzere toplam 46 üniversite kariyer merkezi bulunduğu belirtilmiştir (Zeren ve diğerleri., 2017). Pişkin ve Kart tarafından yürütülen çalışmada ise 2010 yılından önce sadece 6 devlet üniversitesinde kariyer merkezi bulunduğu, 2010 itibari ile bu sayının 20'ye yükseldiği ancak bunların 3'ünde yönetici olarak atanan akademisyen dışında hiç personelin olmadığ 1 ve merkezlerin yarıdan fazlasının 2013 yılından sonra açıldığı bilgisi paylaşılmıştır (Pişkin ve Ersoy Kart, 2019).

Görüldüğü üzere, üniversite kariyer merkezleri hakkında yapılan sınırlı sayıdaki akademik araştırma, söz konusu merkezlerin sayısına ilişskin dahi farklı sonuçlara işaret etmektedir. Çalışmalardaki veriler tarihleri itibari ile karşılaştırmalı olarak değerlendirildiğinde dikkat çekici farklılıklar göze çarpmaktadır. Örneğin; yukarıda da atıfta bulunulan araştırmada, 2015-2016 yıllarında İstanbul'da 5 devlet üniversitesinde kariyer merkezi bulunduğu bilgisi (Zeren ve diğerleri., 2017) paylaş1lırken bundan yaklaşık 4 yıl sonra yapılan araştırmada, İstanbul'da aktif faaliyet gösteren üniversite kariyer merkezi sayısını 4 olarak belirtilmektedir (Pişkin ve Ersoy Kart, 2019).

Yapılan araştırmalar, farklı nicel verilere işaret etse de kariyer merkezi bulunan üniversitelerin verdiği hizmetler ve bu hizmetlerin niteliği hakkında genel bir fikir sahibi olmamıza yardımcı olmaktadır. Mevcut çalışmada; söz konusu merkezlerin sayısal anlamda ne kadar yaygın olduğu bir kenara bırakılarak bu merkezlerin verdiği hizmetlere ilişkin bir değerleme yapabilmek amacı ile araştırmaların sonuçları bir araya getirilmiştir.

Anadolu üniversitesindeki 2901 son sınıf öğrencisi ile 2011 yılında gerçekleştirilen araştırmada; öğrencilerin kariyer kararlarında yeterli desteği alamadıkları tespit edilmiştir (Kozak ve Dalkıranoğlu, 2013).

İstanbul' daki üniversitelerde 2017 yılında gerçekleştirilen çalışmada; üniversite kariyer merkezlerinde verilen hizmetlerin günümüz koşulları için oldukça yetersiz olduğu ifade edilmiştir (Zeren ve diğerleri., 2017). Aynı yıl, Ankara'daki üniversitelerin kariyer merkezlerinin incelendiği çalışmada, görevlendirilen uzman personel sayısının öğrenci sayılarına göre son derece yetersiz olduğu sonucuna ulaşılmış, verilen danışmanlık hizmetlerinde ve yapılan etkinliklerde değişikliğe gidilmesi gerektiğinden bahsedilmiştir (Karaaslan, 2017).

Son olarak; merkez yöneticilerinin liderlik vasfını üstlendiği, dolayısıyla kariyer merkezlerinin faaliyetlerini ne derece ciddiyetle yerine getireceği konusunda önemli rol oynadı̆̆ ve hizmet kalitesinde personel niteliğinin belirleyici olduğu düşünülerek bu yönde bulgular içeren çalışma sonuçlarının paylaşılması uygun görülmüştür. Söz konusu çalışmada (Pişkin ve Ersoy Kart, 2019): merkez yöneticilerinin çoğunlukla kariyer ile ilgili olmayan konulardan seçildiği, bazı yöneticilerin 
merkeze 6 ayda ya da ayda bir uğradığı, merkezde personel olarak görevlendirilmek için belirli bir uzmanlık aranmadığı gibi personele bir eğitim de verilmediği tespit edilmiştir. Ayrıca; sekreter, idari hizmetler gibi kariyer rehberliği ve danışmanlığı hizmetleriyle doğrudan ilgili olmayanlar da dâhil olmak üzere 20 üniversitede toplam 37 personel olduğu, dolayısıyla yaklaşık her 26.000 öğrenciye bir personel düştüğü sonucuna ulaşılmıştır. Araştırmadaki çarpıcı sonuçlardan biri ise merkeze yönetici olarak atanan kişinin, kariyer planlama etkinliklerini ve bunların önemini bilen, alanda uzman kişiler olması halinde merkezlerin fark edilir biçimde daha aktif olduğunun tespit edilmesidir.

Türkiye'de üniversite kariyer merkezleri; rektörlüğe bağlı birimler, rektörlüğe bağlı birimlerin alt birimi ya da üniversite senatosunca kararlaştırılıp YÖK onayı ile resmileşen Uygulama ve Araştırma Merkezi statüsünde kurulabilmektedir. Dolayısıyla, 2019 yılına kadar bu yapılara ilişkin bilgilere tek bir merkezden ulaşmak mümkün değildir. Nitelikli, araştırmaların çok az sayıda olması ve mevcut araştırmaların kısıtları nedeniyle çalışmalardan sadece, ülkemizdeki kariyer merkezlerine ilişkin genel geçer bilgiler edinilebilmektedir. Söz konusu bilgiler ise, kariyer merkezi sayısının, mevcutlardaki personel sayısının ve niteliğinin yetersiz olduğunu ve merkezlerde uygulama birliği bulunmadığını ortaya koymaktadır. Dolayısıyla da, eğitimli gençlerimizin kariyer gelişimlerinde büyük fark yaratma potansiyeli olan kariyer merkezlerinden sayıca ve nitelikçe beklenen faydanın sağlanamadığına işaret etmektedir.

Ancak 2018 yılında; kariyer merkezlerinin yapı ve uygulamalarında gerçekleştirilecek köklü değişiklere ilişkin ilk sinyaller, doğrudan Cumhurbaşkanlığınca verilmiş, 2018-2019 Yükseköğretim Akademik Yılı Açılış Töreninde, üniversitelerin tamamında kariyer merkezleri kurulması ve etkin hizmet üretmeleri için koordine edilmeleri görevinin CBİKO tarafından yürütüleceği duyurulmuştur. Kariyer merkezleri ise; öğrencilere ilk yılından itibaren kariyer konusunda rehberlik edecek, reel sektör ile işbirliği içinde faaliyet gösteren, kamu ve özel sektördeki istihdam imkânlarını öğrencilere tanıtan aktif birimler olarak tanımlanmıştır (TCCB, 2018).

Görevin tevdi edilmesinin ardından CBİKO tarafından gerçekleştirilen mevcut durum analiziyle; ülkemizde faaliyet gösteren kariyer merkezi sayısının Ocak 2019'da 53 olduğu, bunların yarısından fazlasında gerekli personel görevlendirmelerinin yapılmadığı, faaliyetlerini yürütmek için ofislerinin bulunmadığı dolayısıyla pek çoğunun kâğıt üzerinde varlığını sürdüren kurumlar olduğunu tespit etmiştir (CBİKO, 2020).

CBİKO, kariyer merkezlerinin görevlerini, süreçlerini ve kariyer merkezi personelinin rol sorumluluk ve görevlerini ortaya koymak ve ayrıca kariyer merkezleri arasında eşgüdüm sağlamak amacı ile Kariyer Merkezleri Kitabını hazırlayarak üniversite yönetimleri ve kariyer merkezleri ile paylaşmıştır 
(Atay, Çırakoğlu Tanrıverdi ve Gülmez, 2019). Ek olarak, öğrenci, işveren ve kariyer merkezlerinin çevrimiçi buluşabildiği ve hizmetlerden yaralanabildiği yerli bir yazılım hazırlayarak tüm kariyer merkezlerinin hizmetine sunmuştur (AA, 2020). 2020 yılı tarihi itibari ile CBİKO çalışmaları sayesinde, devlet ve vakıf olmak üzere tüm üniversitelerde kariyer merkezleri kurulmuş ve çalışmaya başlamaları sağlanmıştır. Söz konusu kariyer merkezleri Bölgesel Kariyer Fuarları, staj programları gibi faaliyetlerle desteklenmeye devam edilmektedir.

\section{SONUÇ}

Özellikle yükseköğretimdeki gençler ve farklı paydaşlar için kritik role sahip kariyer merkezlerinin hayata geçirilmesinde ilk adımı atan Birleşik Krallıkta tetikleyici faktör, üniversiteleri öğrencilerin refahından sorumlu tutan, kanuni bir doktrindir. Bu doktrin doğrultusunda, üniversiteler öğrencilerinin kariyerlerine destek vermek amacı ile söz konusu birimleri kurmuşlardır. Uygulamada İngiltere'yi takip eden Amerika Birleşik Devletleri kanunlarında da aynı doktrinin yer aldığı ve üniversitelerin bu doğrultuda harekete geçtiği görülmektedir. Avustralya ve Kanada örneklerinin gelişim evreleri incelendiğinde ise, bu evrelerde ortak kültürel dokuya sahip oldukları Birleşik Krallık etkisi olduğu düşünülmektedir.

Kıta Avrupası'nda, kariyer merkezlerinin kurulmasında Bologna Sürecinin etkili olduğunu düşünülmektedir. Özellikle Almanya gibi kariyer planlamayı, erken öğrencilik dönemlerine kadar indirgeyebilmiş ülkeler yükseköğretimde Birleşik Krallık örneğinde görülen kariyer merkezi uygulamasına ihtiyaç duymamıştır. Ancak Almanya üniversiteleri, Bologna Süreci ile etkinleşen Avrupa Birliği üyesi / adayı ülkeleri arasındaki öğrenci hareketliliği nedeni ile, böyle bir kariyer planlamasına sahip olmayan ülkelerden gelen öğrencilere kariyer planlama hizmeti verme ihtiyac1 duymuştur. Fransa'da ise bu ihtiyacı, daralan ekonomi ve artan öğrenci sayısı ile paralel artış gösteren yükseköğretim mezunlarının işsizliği belirgin hale getirmiştir. Aynı zamanda Kıta Avrupası üniversitelerinde, hem yetenekli öğrencileri kendilerine çekme hem de beyin göçünü engelleme ihtiyacı doğrultusunda kariyer merkezleri önem kazanmıştır.

Asya Pasifik ülkelerindeki örnekler ise, söz konusu ülkelerdeki kariyer merkezlerinin kurulmasında ekonomik temelli faktörlerin rol oynağını göstermektedir. Yükseköğretimdeki öğrenci sayının artması ve iş piyasasındaki imkânların daralması, üniversiteleri öğrencilerinin istihdam edilebilirliklerini arttırmaları gerektiği gerçeği ile karşı karşıya bırakmıştır.

Türkiye'de ise; diğer ülkeler için geçerli koşullar oluşmasına rağmen, kariyer merkezleri üniversitelerde çok geç kurulmaya başlanmış ve uzun süre boyunca az sayıda üniversite tarafından hayata geçilen münferit birimler olarak kalmışlardır. Dahası, mevcut olanların da bir amaç 
doğrultusunda planlı şekilde hareket etmediği ve kendilerinden beklenen etkiyi yaratamadıkları görülmektedir. Kariyer Merkezleri, 2018 yılı itibari ile Cumhurbaşkanlığı İnsan Kaynakları Ofisi tarafından yönlendirilmekte, koordine edilmekte ve gerekli araçlar temin edilerek etki alanları geliştirilmeye çalışılmaktadır. Bu kapsamda, kısa zamanda kat edilen; üniversitelerin tamamında kariyer merkezlerinin açılması, nasıl çalışılması gerektiği ile ilgili teorik altyapının oluşturulması ve etkin hizmet sunabilmek için dijital araçların temin edilmesi gibi çalışmalar göz önünde bulundurulduğunda, ülkemizdeki ve gelişmiş ekonomilerdeki kariyer merkezi hizmetleri arasındaki nitelik ve nicelik farkının hızla kapanması beklenmektedir. 


\section{KAYNAKÇA}

AA. (2020). Çevrim içi kariyer platformu 'Yetenek Kapısı' tarafların kullanımına açıldı. Retrieved from https://www.aa.com.tr/tr/turkiye/cevrim-ici-kariyer-platformuyetenek-kapisi-taraflarin-kullanimina-acildi/1847537

Atay, S., Çırakoğlu Tanrıverdi, B., \& Gülmez, N. (2019). Üniversite Kariyer Merkezleri. Ankara: Salmat Basım Yay. Amb. San.Tic.Ltd. Şti.

Baltan, N. (1985, Ocak 1985). Mezunlara İş Bulma Bürosu. Katılım Dergisi, 3, 1-23. Retrieved from http://tustav.org/yayinlar/sureli_yayinlar/katilim/katilim_3.pdf

Bara Stolzenberg, E., Aragon, M. C., Romo, E., Couch, V., McLennan, D., Eagan, M. K., \& Kang, N. (2020). The American Freshman: National Norms Fall 2019. Los Angeles, California

Barbour, K. L. (2016). Exploring the impact of change on university Careers Services: death of a service or surviving and thriving? University of Glasgow.

Bezanson, L., Hopkins, S., \& Neault, R. A. (2016). Career guidance and counselling in Canada: Still changing after all these years. Canadian Journal of Counselling and Psychotherapy, 50(3).

Bilkent-KM. (t.y.). Hakkımızda. Retrieved from http://kariyer.bilkent.edu.tr/hakkimizda/\#

Bishops, J. (1966). Portents in college placement. College student.

Brandl, K., Polenova, E., \& Savoca, M. (2011). American vs. German Tradition: Different Approaches in Career Counseling and Career Services. In Anzeige Berufsstart (pp. 55-60): Career Service Netzwerk Deutschland e. V.

Browne, J., \& Russell, L. (2014). The practice of postsecondary career development. Career development practice in Canada: Perspectives, principles, and professionalism, 361-382.

Carlson, S. (2017). How colleges prepare students for the work force. The Chronicle of Higher Education, 63(34), A30.

Castella, D. A. (1990). Career Networking: The Newest Career Center Paradigm. Journal of Career Planning and Employment, 50(4), 32-39.

CBİKO. (2020). Kariyer Merkezleri ile İlgili Yürütülen Çalışmalar - Bilgi Notu. T.C. Cumhurbaşkanlığı İnsan Kaynakları Ofisi Başkanlığı.

$\begin{array}{llll}\text { CCLC. } & \text { (t.y.). History. } & \text { Retrieved }\end{array}$ https://snucounsel.snu.ac.kr/en/enintro/introHistory.do

Cox, D. H., \& Strange, C. C. (2010). Achieving student success: Effective student services in Canadian higher education: McGill-Queen's Press-MQUP. 
Crosier, D., Horvath, A., Kerpanova, V., Kocanova, D., \& Riihelainen, J. (2015). Modernisation of Higher Education in Europe: Access, Retention and Employability. Eurydice Brief. Education, Audiovisual and Culture Executive Agency, European Commission.

Domene, J. F., \& Isenor, J. (2017). Career service provision in Canada: Deep roots and diverse practices. International practices of career services, credentials, and training, 1-9.

Eurogudience. (t.y.). Guidance System in France. Retrieved from https://www.euroguidance.eu/guidance-system-in-france

Eurydice. (2018). Guidance and Counselling in Higher Education - France. Retrieved from https://eacea.ec.europa.eu/national-policies/eurydice/france/guidance-andcounselling-higher-education_en

Geisler, B. (2002). A brief history of vocational guidance \& college career services. Retrieved from https://www.newfoundations.com/History/GeislerHist.html

Gillani, S. A., \& Keller, S. (2018). Career Services: A Best-Practice example from Germany. In M. Boachie-Mensah, Scheuer (Ed.), Handbook of Applied Market Research and Personnel Services at Universities (pp. 43-47): Hochschule BonnRhein-Sieg.

Gonzales, M. (2017). Examining institutional career preparation: Student perceptions of their workplace readiness and the role of the university in student career development. (PhD). Pepperdine University, (10258395)

Han, S., \& Heo, J. (2008). Career counseling on campus in South Korea. Career Planning \& Adult Development Journal, 24(4), 57-64.

Hao, D., Sun, V. J., \& Yuen, M. (2015). Towards a model of career guidance and counseling for university students in China. International Journal for the Advancement of Counselling, 37(2), 155-167.

Hooley, T., Hutchinson, J., \& Watts, A. G. (2010). Careering through the web. The potential of Web 2.0 and 3.0 technologies for career development and career support services. An Expert Paper prepared for UKCES. University of Derby: International Centre for Guidance Studies.

Ishikawa, Y., Mizuno, M., \& Amundson, N. E. (2009). Career awareness of new graduates and recruiting activities by companies in Japan. journal of employment counseling, 46(2), 62-72.

Jenschke, B., Schober, K., \& Langner, J. (2014). Career guidance in the life course: Structures and services in Germany. Retrieved from Bielefeld: W. Bertelsmann Verlag.

Jin, L. (2017). The current status of career services and professionals in mainland China's educational settings. International practices of career services, credentialing, and 
training.

Retrieved

https://ncda.org/aws/NCDA/asset_manager/get_file/156398

from

Kaneko, M. (2014). Higher Education and Work in Japan: Characteristics and Challenges. Japan Labor Review, 11(2), 5-22.

Karaaslan, S. (2017). Ankara'daki Üniversitelerin Kariyer Merkezleri Üzerine Bir Değerlendirme. Retrieved from https://www.researchgate.net/publication/313051152

Kawasaki, T. (2006). Problems in career services at Japanese universities: A case study of initiatives at Kansai University. Japan Labor Review, 3(2), 43.

KLRI-KLT. (2015). Career Education Act. Retrieved from https://elaw.klri.re.kr/eng_service/lawView.do?hseq=38018\&lang=ENG

Koder, M. (1991). Careers advisory services in higher education institutions: Report of the National Board of Employment, education and training and the Department of Employment, education and training. In: Canberra, Australia: Australian Government Publishing Service.

Kozak, M. A., \& Dalkıranoğlu, T. (2013). Mezun Öğrencilerin Kariyer Algılamaları: Anadolu Üniversitesi Örneği. Anadolu University Journal of Social Sciences, 13(1).

Lee, J.-K., \& Goh, M. (2003). Career counseling centers in higher education: A study of cross-cultural applications from the United States to Korea. Asia Pacific Education Review, 4(1), 84-96.

Lee, J.-Y. (2001). Career guidance at higher education level in Korea. Seoul, Korea: Korea Research Institute for Vocational Education \& Training.

Lee, P. (2011). The curious life of in loco parentis at American universities. Higher Education in Review, 8, 65-90.

Long, R., Hubble, S., \& Loft, P. (2020). Careers guidance in schools, colleges and universities. Retrieved from https://dera.ioe.ac.uk/34933/1/CBP$7236 \% 20 \% 281 \% 29 . p d f$

Mckenzie, M., \& Howell, J. (2005). A snapshot of Australian university career services. Australian Journal of Career Development, 14(2), 6-14.

Mimura, T. (2016). Vocational Guidance, Career Guidance, and Career Education phases in Japan. 早稲田大学大学院教職研究科紀要(8), 19-34.

Mizuno, S., Ozawa, Y., \& Matsumoto, K. (2017). Career Services and Professionals in Japan. International practices of career services, credentials, and training., 1-7. Retrieved from http://careerconvergence.com/aws/NCDA/asset_manager/get_file/156345?ver=40 8 
NACE. (2019). The Professional Standards For College \& University Career Services. National Association of Colleges and Employers (NACE). https://www.naceweb.org/career-development/standardscompetencies/professional-standards-for-career-services/.

Niles, S. G., \& Harris-Bowlsbey, J. (2002). Career development interventions in the 21st Century. Upper Saddle River, NJ: Merrill Prentice Hall.

ODTÜ-KPM. (t.y.). Hakkımızda. Retrieved from https://kpm.metu.edu.tr/hakkimizda/

OECD. (2002). Review of Career Guidance Policies. South Korea: Country Note. OECD. http://www.oecd.org/oecd/pages/home/displaygeneral/0,3380,EN-document-59217-no-21-17182-592-no-no,FF.html.

OECD. (2019). OECD Employment Outlook 2019: The future of work: OECD Publishing.

OECD. (2020a). Education at a Glance 2020.

OECD. (2020b). Unemployment Rates by Education Level. Retrieved from https://data.oecd.org/unemp/unemployment-rates-by-educationlevel.htm\#indicator-chart

Onne Kraning, J. (1999). Career centers: Changing needs require changing paradigms. Colorado State University Journal of Student AtTairs Volume VllI, 1999, 8, 77.

Özden, M. C. (2015). Üniversite Yönetmelikleri Çerçevesinde Kariyer Merkezlerinin Organları Ve Görevleri. Giresun Üniversitesi İktisadi ve İdari Bilimler Dergisi, $1(2), 111-136$.

Paul, J.-J., \& Murdoch, J. (2000). Higher education and graduate employment in France. European Journal of Education, 35(2), 179-187.

Pişkin, M., \& Ersoy Kart, M. (2019). Üniversite Kariyer Merkezlerinin Örgüt Yapısı ve Personel Profilinin İncelenmesi: Kimler Yönetiyor? Kimler Yürütüyor? SGDSosyal Güvenlik Dergisi, 9(2), 275-298.

Pope, M. (2000). A brief history of career counseling in the United States. The Career Development Quarterly, 48(3), 194-211.

Rainey, L., Simons, M., Pudney, V., \& Hughes, E. (2008). What choice? An evaluation of career development services for young people: National Centre for Vocational Education Research.

Royal, D. (2020). Impacts and Perceptions of Career-Focused Education.

Saito, E., \& Pham, T. (2020). A comparative institutional analysis on strategies deployed by Australian and Japanese universities to prepare students for employment. Higher Education Research \& Development, 1-15. 
Schoenberg, B. M. (1978). A handbook and guide for the college and university counseling center: Greenwood.

Senzaki, T. (1993). Career education in Japan: Its current status and condition. The Career Development Quarterly, 41(4), 291-296.

Shepard, B. C., \& Mani, P. S. (2013). Career development practice in Canada: Perspectives, principles, and professionalism: Canadian Education and Research Institute for Counselling.

Sun, V. J., \& Yuen, M. (2012). Career guidance and counseling for university students in China. International Journal for the Advancement of Counselling, 34(3), 202-210.

Szablewicz, J. J., \& Gibbs, A. (1987). Colleges' increasing exposure to liability: The new In Loco Parentis. JL \& Educ., 16, 453.

TCCB. (2018). Yükseköğretim Akademik Y1lı Açılış Töreninde Yaptıkları Konuşma. Retrieved from https://www.tccb.gov.tr/konusmalar/353/99365/yuksekogretimakademik-yili-acilis-toreninde-yaptiklari-konusma

Teal, E., \& Herrick, R. (1962). The fundamentals of college placement. Bethlehem, PA.

Tomei, N., Carp, B., \& Kröner, S. (2015). Guidance and counselling in higher education: A comparison between the career services in Germany and Italy. Adult Education and Lifelong Learning in Europe and Beyond, 195.

Trines, S. T. (2019). How Germany Became an International Study Destination of Global Scale. World Education News + Reviews.

UNESCO. (1994). Counselling and Orientation of Students in Higher Education https://unesdoc.unesco.org/ark:/48223/pf0000155712.

Usher, A., Kwong, A., \& Mentanko, J. (2014). Career Services Offices: A Look at Universities and Colleges across Canada. Toronto: Higher Education Strategy Associates.

Vinson, B. M., Reardon, R. C., \& Bertoch, S. C. (2014). Career services at colleges and universities: A 30-year replication study. Journal of College Student Development, 55(2), 203-207.

Watanabe-Muraoka, A. M. (1996). The national system of university counselling in Japan. International Journal for the Advancement of Counselling, 19(1), 15-27.

Watanabe-Muraoka, A. M., Senzaki, T.-A. T., \& Herr, E. L. (2001). Donald Super's contribution to career guidance and counselling in Japan. International Journal for Educational and Vocational Guidance, 1(1-2), 99-106.

Watts, A. (1994). The Changing Role Of Careers Services In Higher Education In The United Kingdom. Higher Education in Europe, 19(3), 73-83. 
Watts, A., \& Van Esbroeck, R. (2000). New skills for new futures: a comparative review of higher education guidance and counselling services in the European Union. International Journal for the Advancement of Counselling, 22(3), 173-187.

Watts, A. G. (1996). The changing place of careers guidance in schools. European Education, 28(2), 21-34.

Watts, A. G., Hawthorn, R., Law, B., Killeen, J., \& Kidd, J. M. (1996). Rethinking careers education and guidance: theory, policy and practice: Psychology Press.

Watts, A. G., \& Kidd, J. M. (2000). Guidance in the United Kingdom: Past, present and future. British Journal of Guidance \& Counselling, 28(4), 485-502.

Yang, E., Lee, S. M., \& Ahn, S.-S. (2012). Career centers in higher education in South Korea: Past, present, and future. Asian journal of Counselling, 19(1), 2-53.

Yoon, H. J., \& Pyun, C.-H. (2018). The status of career development in South Korea: Qualifications for career professionals. 2018). International practices of career services, credentials, and training, 137-159.

Zeren, Ş. G., Amanvermez, Y., Buyruk Genç, A., Ermumcu, E., Kalay, T., Satıcı, B., \& Y1lmaz, A. S. (2017). Yükseköğretimde Kariyer Merkezlerinin İncelenmesi: İstanbul İli Örneği. Journal of Higher Education \& Science/Yüksekögretim ve Bilim Dergisi, 7(3).

Zhang, W., Hu, X., \& Pope, M. (2002). The evolution of career guidance and counseling in the People's Republic of China. The Career Development Quarterly, 50(3), 226236. 